Journal of Science

and Engineering

Full Paper

\section{ANALISIS MODEL DESAIN BANGUNAN BANK SAMPAH DI KELURAHAN TARAU KECAMATAN KOTA TERNATEUTARA}

Ardi Basria ${ }^{\text {, Asri A. Muhammad }}$, Hery Purnomo ${ }^{\text {c* }}$

aUniversitas Khairun, Ternate, Indonesia

bUniversitas Khairun, Ternate, Indonesia

cUniversitas Khairun, Ternate, Indonesia
Article history

Received

10 Juli 2021

Received in revised form

2 September 2021

Accepted

18 Oktober 2021

*Corresponding author Arditektur@gmail.com

\section{Graphical abstract}

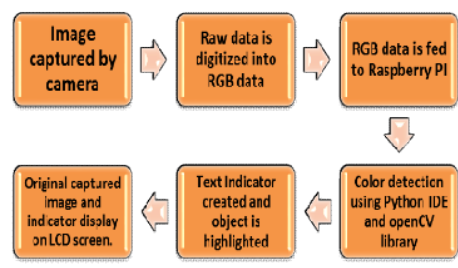

\begin{abstract}
Garbage is a latent problem that occurs in Indonesia. the waste problem is a shared responsibility between the government and the community. Through the Regulation of the State Minister for the Environment of the Republic of Indonesia Number 13 of 2012 concerning Guidelines for the Implementation of Reduce, Reuse and Recycle through a Waste Bank, it is an alternative to tackling the waste problem. Waste Bank can be optimized at the urban village level according to the standards set in the Permen LH no. 13/2012. Kelurahan Tarau in North Ternate Subdistrict has one Garbage Bank whose management is still individual and does not meet the standards of government regulations. Through this research, it is hoped that the Garbage Bank building in Tarau Village can be optimized in terms of management and building standards and can be an alternative solution to the waste problem in the city of Ternate. The research method used is descriptive qualitative research with a case study approach to be able to answer the objectives of this study with the stages of field surveys, data analysis, concept design and design stages. Meanwhile, the purpose of this research is to design a Garbage Bank building according to the standards of the Regulation of the Minister of Environment of the Republic of Indonesia Number 13 of 2012.
\end{abstract}

Keywords: Garbage Bank, Kelurahan Tarau, Standard, Ternate

\section{Abstrak}

Sampah merupakan permasalahan laten yang terjadi di Indonesia. permasalahan sampah menjadi tanggung jawab bersama antara pemerintah dan masyarakat. Melalui Peraturan Menteri Negara Lingkungan Hidup Republik Indonesia Nomor 13 Tahun 2012 Tentang Pedoman Pelaksanaan Reduce, Reuse, dan Recycle Melalui Bank Sampah, menjadi salah satu alternatif penanggulangan masalah sampah. Bank Sampah dapat dioptimalkan di tingkat kelurahan sampai perkotaan sesuai dengan standard yang telah di tetapkan dalam Permen LH no. 13 tahun 2012. Kelurahan Tarau di Kecamatan Ternate Utara, memiliki satu buah Bank Sampah yang pengelolaannya masih bersifat individu dan belum memenuhi standard dari peraturan pemerintah. Melalui penelitian ini, diharapkan bangunan Bank Sampah yang ada di Kelurahan Tarau dapat dioptimalkan secara pengelolaan maupun standard bangunan dan dapat menjadi salah satu alternatif solusi permasalahan sampah di kota Ternate. Metode penelitian yang digunakan adalah penelitian deskriptif kualitatif dengan pendekatan studi kasus untuk dapat menjawab tujuan dari penelitian ini dengan tahapan survey lapangan, analisis data, konsep rancangan dan tahap desain. Sedangkan tujuan dari penelitian ini adalah mendesian bangunan Bank Sampah sesuai standard Peraturan Menteri Negara Lingkungan Hidup Republik Indonesia Nomor 13 Tahun 2012.

Kata kunci: Bank Sampah, Kelurahan Tarau, Standard, Ternate

(C) 2018 Penerbit Fakultas Teknik Unkhair. All rights reserved 


\subsection{LATAR BELAKANG}

Permasalahan sampah selama ini telah menjadi isu Nasional dan menjadi permasalahan penting di lingkungan perkotaan. Sampah akan terus menjadi permasalahan dan tidak pernah berkurang dan pasti terus bertambah seiring dengan bertambahnya populasi manusia [1] .

Data yang tercatat dalam Kementerian Lingkungan Hidup, rata-rata masyarakat Indonesia menghasilkan 2.5 Liter sampah perhari ditotal sebanyak 625 juta liter sampah yang dihasilkan perhari. Kejadian ini akan terus bertambah seiring dengan pertambahan penduduk dan sesuai dengan kondisi lingkungan. Statistik sampah Indonesia 2012, mencatat jumlah sampah yang timbul di seluruh wilayah Indonesia mencapai 38,5 Juta Ton pertahun. Dengan didominasi oleh Pulau Jawa yang menghasilkan 21,2 Juta Ton pertahun [Q ].

Kota Ternate adalah salah satu kota yang sedang berkembang di Propinsi Maluku Utara. Penduduk Kota Ternate berdasarkan proyeksi penduduk tahun 2017 sebanyak 223.111 jiwa yang terdiri atas 113.334 jiwa penduduk laki-laki dan 109.777 jiwa penduduk perempuan. Kepadatan penduduk di Kota Ternate tahun 2017 mencapai 1.797 jiwa/km2. Kepadatan Penduduk di 8 kecamatan cukup timpang, dengan kepadatan penduduk tertinggi terletak di kecamatan Ternate Tengah dengan kepadatan sebesar $5.842 \mathrm{jiwa} / \mathrm{km} 2$, kecamatan Ternate Selatan dengan kepadatan sebesar 4.522,61 jiwa/km2, kecamatan Ternate Utara dengan kepadatan sebesar 3.794,23 jiwa/km2 dan terendah di Kecamatan Pulau Batang Dua sebesar 98 jiwa/km2. Persebaran penduduk yang kurang merata, membuat kepadatan penduduk terkonsentrasi di wilayah Kecamatan Ternate Tengah, Selatan dan Utara karena menjadi pusat pemerintahan, pendidikan, dan ekonomi [3].

Dengan kepadatan penduduk yang terkosentarsi di tiga kecamatan, akan menimbulkan permasalahan kependuduka yang juga tidak merata di kota Ternate. Salah satu permasalahan kependudukan adalah peningkatan sampah yang seiring dengan pertumbuhan penduduk.Hal tersebut diperparah dengan ketersediaan pengangkutan sampah. Menurut [4], jumlah ketersediaan prasarana pengangkutan (mobil sampah) di kota Ternate hanya mampu mengangkut timbulan sampah sebesar $214 \mathrm{~m}^{3} /$ hari.

Berdasarkan data Kementerian Lingkungan Hidup di atas, dapat dihitung jumlah sampah yang dihasilkan oleh ketiga kecamatan tersebut adalah $14,158.84 \times 2.5$ Liter $=3539,71 \mathrm{~m}^{3} /$ hari. Berdasarkan perhitungan tersebut sangat nampak terihat penumpukkan sampah yang terjadi setiap harinya di tiga kecamatan tersebut.

Kegiatan untuk mengurangi sampah antara lain adalah, pemanfaatan kembali sampah, pendauran ulang, atau yang lebih dikenal dengan istilah Reduce, Reuse dan Recycle (3R) [2]. Dalam Peraturan Menteri Negara Lingkungan Hidup Republik Indonesia Nomor 13 Tahun 2012, menjelaskan bahwa pengelolaan sampah selama ini belum menerapkan prinsip reduce, reuse, dan recycle sehingga menimbulkan dampak negatif terhadap kesehatan masyarakat dan lingkungan. Prinsip reduce, reuse, dan recycle dapat dilaksanakan melalui Bank Sampah.

Kelurahan Tarau adalah salah satu Kelurahan yang berada di wilayah kecamatan Ternate Utara yang memiliki Bank Sampah namun pengelolaannya masih dilakukan oleh individu dan masih bersifat konvensional.Kondisi ini sangat memprihatinkan karena kebutuhan untuk pengelolaan sampah sangat dibutuhkan untuk menyelesaikan permasalahan di atas.

\subsection{KAJIAN TEORI}

2.1 Peraturan Menteri Negara Lingkungan Hidup Republik Indonesia Nomor 13 Tahun 2012 Tentang Pedoman Pelaksanaan Reduce, Reuse, Dan Recycle Melalui Bank Sampah[5]

Pasal 1 : Dalam Peraturan Menteri ini yang dimaksud dengan:

1. Kegiatan reduce, reuse, dan recycle atau batasi sampah, guna ulang sampah dan daur ulang sampah yang selanjutnya disebut Kegiatan $3 \mathrm{R}$ adalah segala aktivitas yang mampu mengurangi segala sesuatu yang dapat menimbulkan sampah, kegiatan penggunaan kembali sampah yang layak pakai untuk fungsi yang sama atau fungsi yang lain, dan kegiatan mengolah sampah untuk dijadikan produk baru.

2. Bank sampah adalah tempat pemilahan dan pengumpulan sampah yang dapat didaur ulang dan/atau diguna ulang yang memiliki nilai ekonomi.

3. Extended Producer Responsibility yang selanjutnya disingkat EPR adalah strategi yang didisain dalam upaya mengintegrasikan biaya lingkungan ke dalam seluruh proses produksi suatu barang sampai produk itu tidak dapat dipakai lagi sehingga biaya lingkungan menjadi bagian dari komponen harga pasar produk tersebut. Pasal 4:

(1) Persyaratan bank sampah sebagaimana dimaksud dalam Pasal 3 huruf a paling sedikit meliputi persyaratan: a. konstruksi bangunan; dan b. sistem manajemen bank sampah.

Pasal 5 : Mekanisme kerja bank sampah meliputi:

a. pemilahan sampah;

b. penyerahan sampah ke bank sampah;

c. penimbangan sampah; 
d. pencatatan;

e. hasil penjualan sampah yang diserahkan dimasukkan ke dalam buku tabungan; dan

f. bagi hasil penjualan sampah antara penabung dan pelaksana.

\subsection{Pengertian Bank Sampah}

Bank sampah lahir dari program Jakarta Green and Clean yaitu salah satu cara pengelolaan sampah skala rumah tangga, yang menitik beratkan pada pemberdayaan masyarakat dalam mengelola sampah rumah tangga. Bank sampah adalah tempat menabung sampah yang telah terpilih menurut jenis sampah, sampah yang ditabung pada bank sampah adalah sampah yang mempunyai nilai ekonomis. Cara kerja bank sampah pada umumnya hampir sama dengan bank lainnya, ada nasabah, pencatatan pembukuan dan manajemen pengelolaannya, apabila dalam bank yang biasa kita kenal yang disetorkan nasabah adalah uang akan tetapi dalam bank sampah yang disetorkan adalah sampah yang mempunyai nilai ekonomis, sedangkan pengelola bank sampah harus orang kreatif dan inovatif serta memiliki jiwa kewirausahaan agar dapat meningkatkan pendapatan masyarakat.Sistem kerja bank sampah pengelolaan sampahnya berbasis rumah tangga, dengan memberikan reward kepada yang berhasil memilah dan menyetorkan sejumlah sampah (Unilever Green\&Clean, 2010).

Bank sampah menjadi metode alternatif pengelolaan sampah yang efektif, aman, sehat dan ramah lingkungan. Hal ini dikarenakan pada bank sampah, masyarakat menabung dalam bentuk sampah yang sudah dikelompokkan sesuai jenisnya sehingga dapat memudahkan pengelolaan bank sampah dalam melakukan pengelolaan sampah seperti pemilahan dan pemisahan sampah berdasarkan jenisnya sehingga tidak terjadi pencampuran antara sampah organic dan non organik yang membuat bank sampah lebih efektif, aman, sehat dan ramah lingkungan (Unilever Green\&Clean, 2010).

Konsep bank sampah ini tidak jauh berbeda dengan konsep 3R (Reduse, Reuse, Recycle). Jika dalam konsep 3R ditekankan bagaimana agar mengurangi jumlah sampah yang ditimbulkan dengan menggunakan atau mendaur ulangnya, dalam konsep bank sampah ini, paling ditekankan adalah bagaimana agar sampah yang sudah dianggap tidak berguna dan tidak memiliki manfaat dapat memberikan manfaat tersendiri dalam bentuk uang, sehingga masyarakat termotivasi untuk memilah sampah yang mereka hasilkan. Proses pemilahan inilah yang mengurangi jumlah timbunan sampah yang dihasilkan dari rumah tangga sebagai penghasil sampah terbesar di perkotaan. Konsep Bank Sampah membuat masyarakat sadar bahwa sampah memiliki nilai jual yang dapat menghasilkan uang, sehingga mereka peduli untuk mengelolanya, mulai dari pemilahan, pengomposan, hingga menjadikan sampah sebagai barang yang bisa digunakan kembali dan bernilai ekonomis [6]

Konsep bank sampah ini menjadi salah satu solusi bagi pengelolaan sampah di Indonesia yang masih bertumpu pada pendekatan akhir. Dengan program ini, sampah mulai dikelola dari awal sumber timbunan sampah, yaitu rumah tangga. Pemilihan yang dilakukan oleh masyarakat sejak awal membuat timbunan sampah yang dihasilkan dan dibawa ke tempat pembuangan akhir (TPA) menjadi berkurang (Medan Green\&Clean, 2010).

Keberadaan bank sampah mampu memberikan nilai ekonomis bagi warga masyarakat. Bank sampah merupakan sentra pengumpulan sampah non organik yang mempunyai nilai harga diantaranya : (kertas, botol plastik, gelas plastik, kardus, plastik kemasan, plastik kresek, koran, plastik sachetan, ember, kaleng, besi, aluminium, dll). Jenis sampah non ini mempunyai nilai harga yang berbeda berdasarkan jenisnya. Harga sangat beragam mulai dari Rp. 100,- per kg sampai Rp. 8.000,- (Medan Green\&Clean, 2010).

\subsection{Keaslian Penelitian}

Dalam meneliti keaslian penelitian Analisis Model Desain Bangunan Bank Sampah Di Kelurahan Tarau Kecamatan Kota Ternate Utara, peneliti menggunakan data yang bersumber dari tinjauan pustaka dan referensi yang relevan dan terkini dengan mengutamakan hasil penelitian pada jurnal-jurnal ilmiah terbaru lima tahun terakhir. Adapun penelusuran rekam jejak penelitian (state of the art) sejenis yang telah dilaksanakan di luar maupun dalam Kota Ternate adalah sebagai berikut :

[7], "Sampah Rumah Tangga di Ternate”. Dimuat dalam Jurnal Techo LPPM Unkhair Volume 7 Nomor 1 Mei 2018 E-ISSN 2580 - 7129. dalam penelitian ini menguraikan tentang deskripsi potensi sampah dan pengenalan komposisi dan timbulan sampah di kota Ternate.

[8], "model skematik desain bangunan Bank Sampah di Depok Jawa Barat”. Dimuat dalam Jurnal Teknik Sipil Dan Lingkungan Volume 2 Nomor 1 April 2017. dalam penelitian ini menjelaskan tentang Menghasilkan prototype bangunan Bank Sampah berdasarkan identifikasi kegiatan dari para pengguna.

[4], "Sistem Pengelolaan dan Upaya Penanggulangan Sampah Di Kelurahan DufaDufa Kota Ternate”. Dimuat dalam Jurnal Bioedukasi Volume 4 Nomor 2 Maret 2016. dalam penelitian ini menjelaskan tentang Pola pengumpulan sampah Kota Ternate, faktor-faktor penghambat yang mempengaruhui sistem pengelolaan sampah di Kelurahan Dufa-Dufa.

Berdasarkan hasil penelusuran rekam jejak penelitian (state of the art), menunjukan bahwa belum ada satupun penelitian yang membahas tentang Analisis Model Desain Bangunan Bank Sampah Di Kelurahan Tarau Kecamatan Kota Ternate Utara dengan pendekatan standard Peraturan Menteri Negara Lingkungan Hidup 
Republik Indonesia Nomor 13 Tahun 2012 Tentang Pedoman Pelaksanaan Reduce, Reuse, Dan Recycle Melalui Bank Sampah .

\subsection{HASIL DAN PEMBAHASAN}

\subsection{Analisis Model Desain Bangunan Bank Sampah}

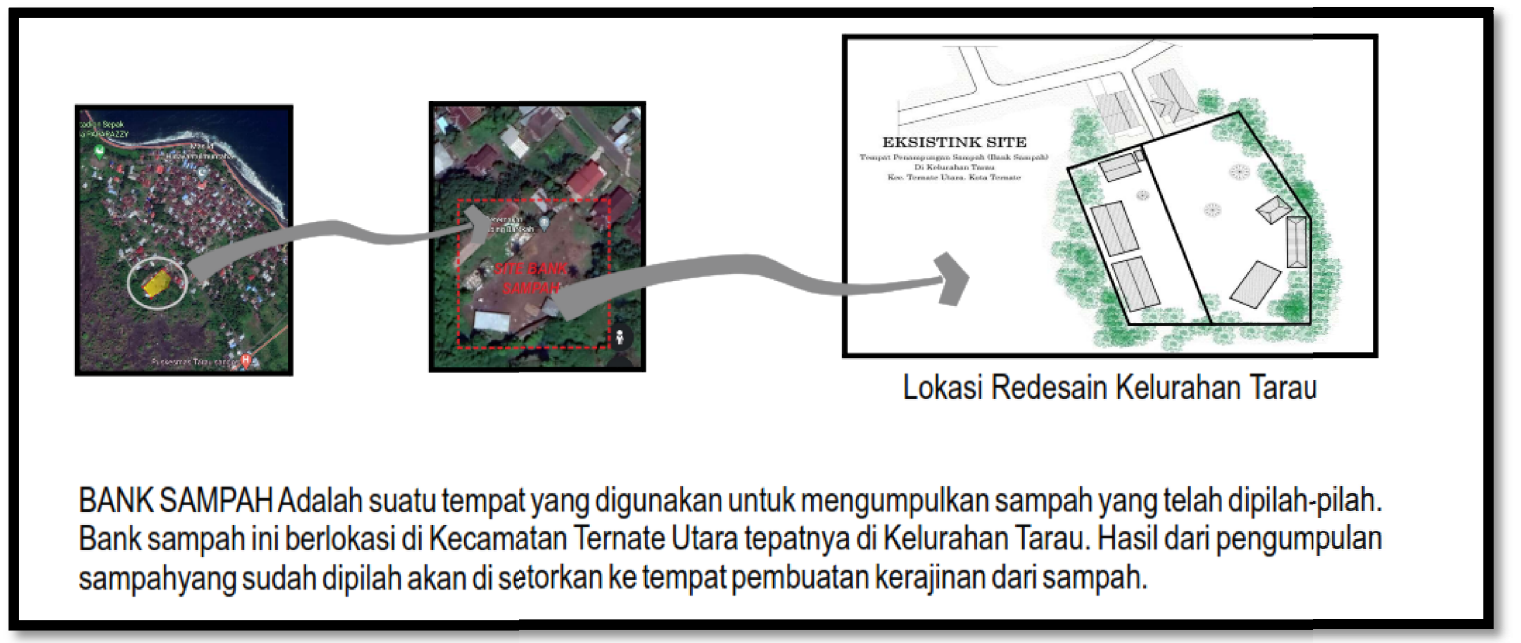

Gambar 1 Lokasi Site

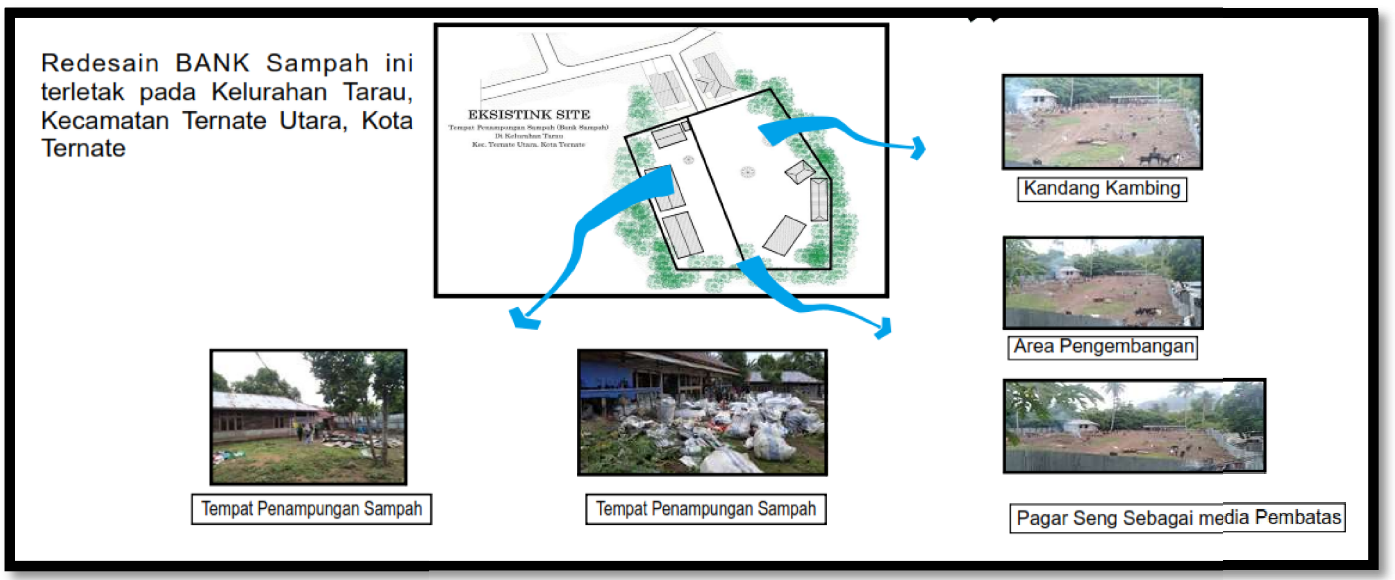

Gambar 2 Eksisting Site

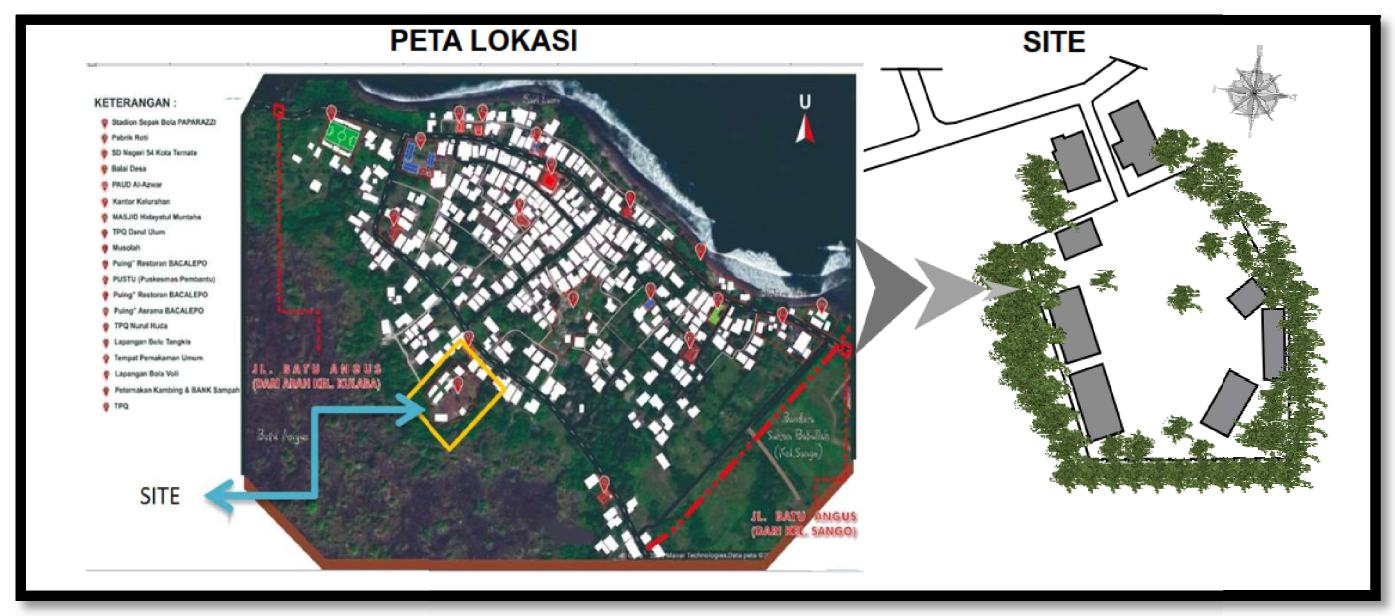

Gambar 3 Analisis Pencapaian 


\section{JALUR UTAMA KE ARAH SITE}

Pencapaian ke area tapak / site direncanakan hanya melalui 1 jalur masuk, begitu juga dengan area keluar, direncanakan hanya melalui 1 jalur. Hal Ini didasarkan pada situasi jalur area yang berada pada lokasi, dan sekaligus mengurangi kemacetan pada area sekitar tapak.

Pencapaian ke area tapak / site bisa melalui dengan berjalan kaki melalui jalur pedestrian yang ada pada area j site, ataupun juga bisa dengan kendaaran melalui jalan raya yang ada site.

\section{JALUR MASUK KE ARAH SITE}

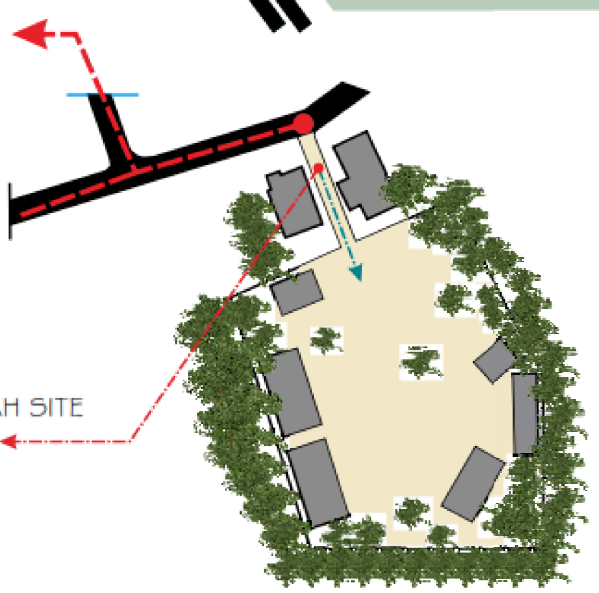

Gambar 4 Analisis Pencapaian Lanjutan

Pada lokasi atau site perancangan masih terdapat vegetasi yang alami yang berada pada sisi Selatan, Barat dan Timur sedangkan pada sisi Utara terdapat pemukiman warga
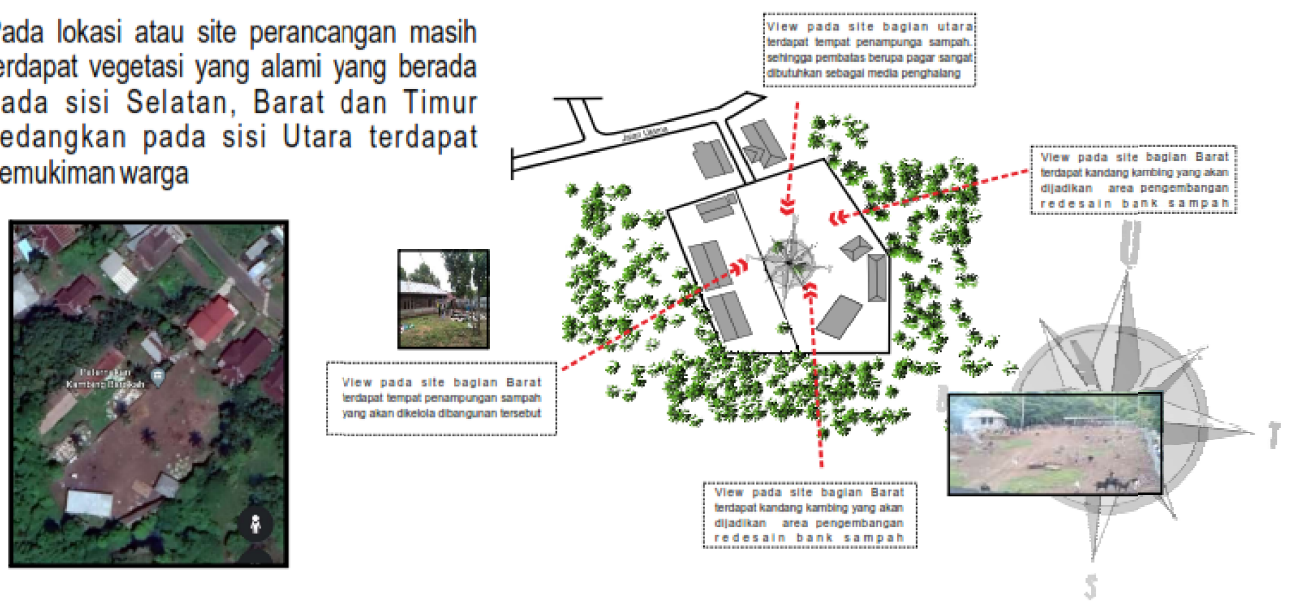

Gambar 5 Analisis Pencapaian Lanjutan

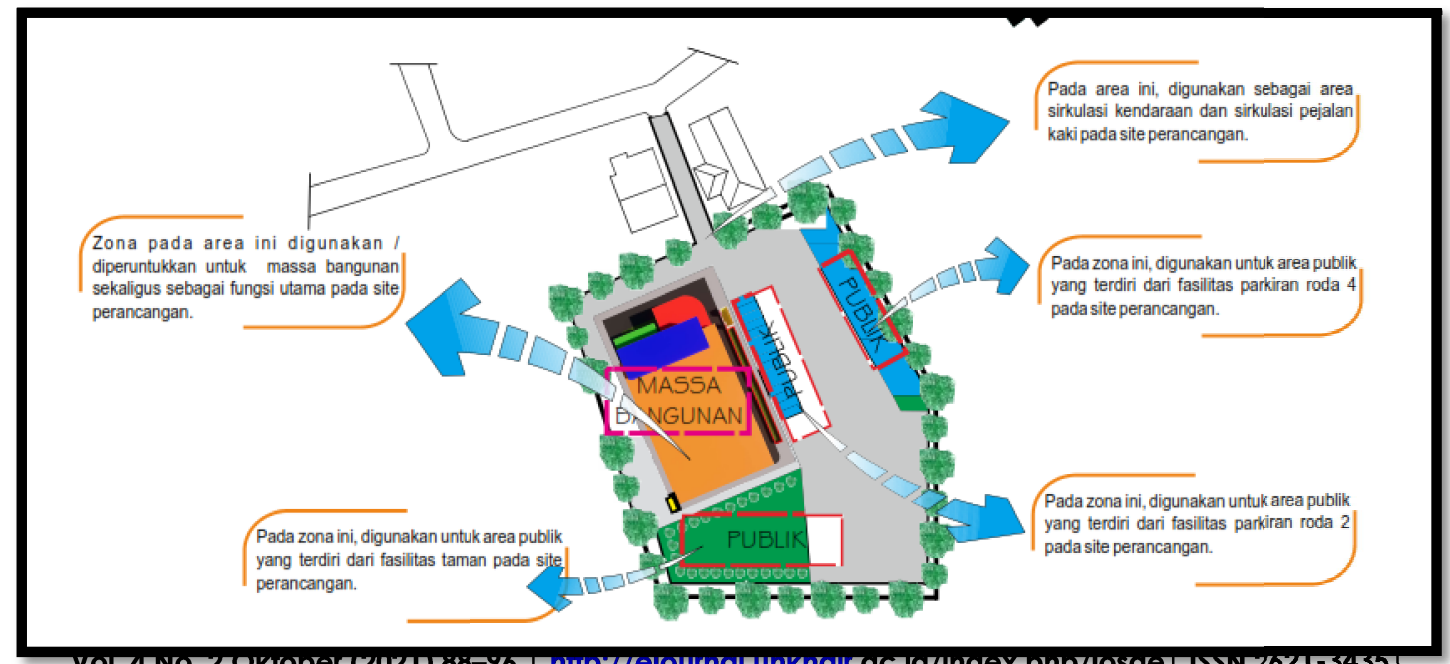




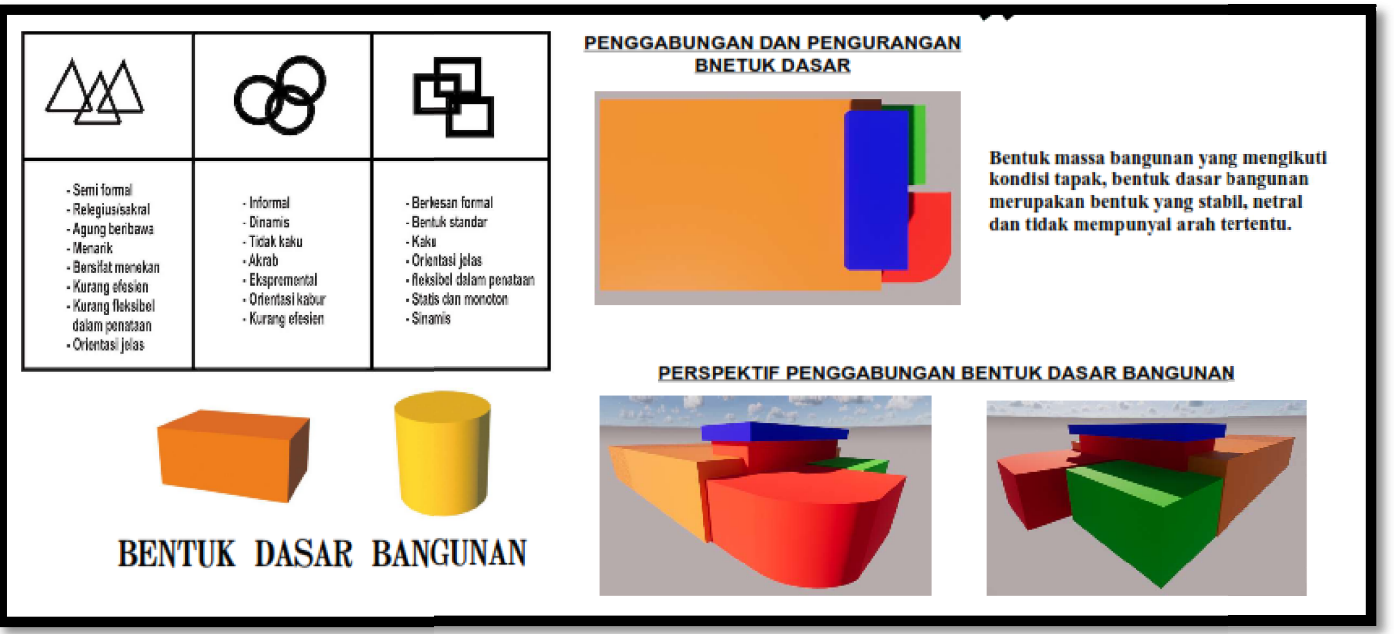

Gambar 7Analisis Bentuk Dasar

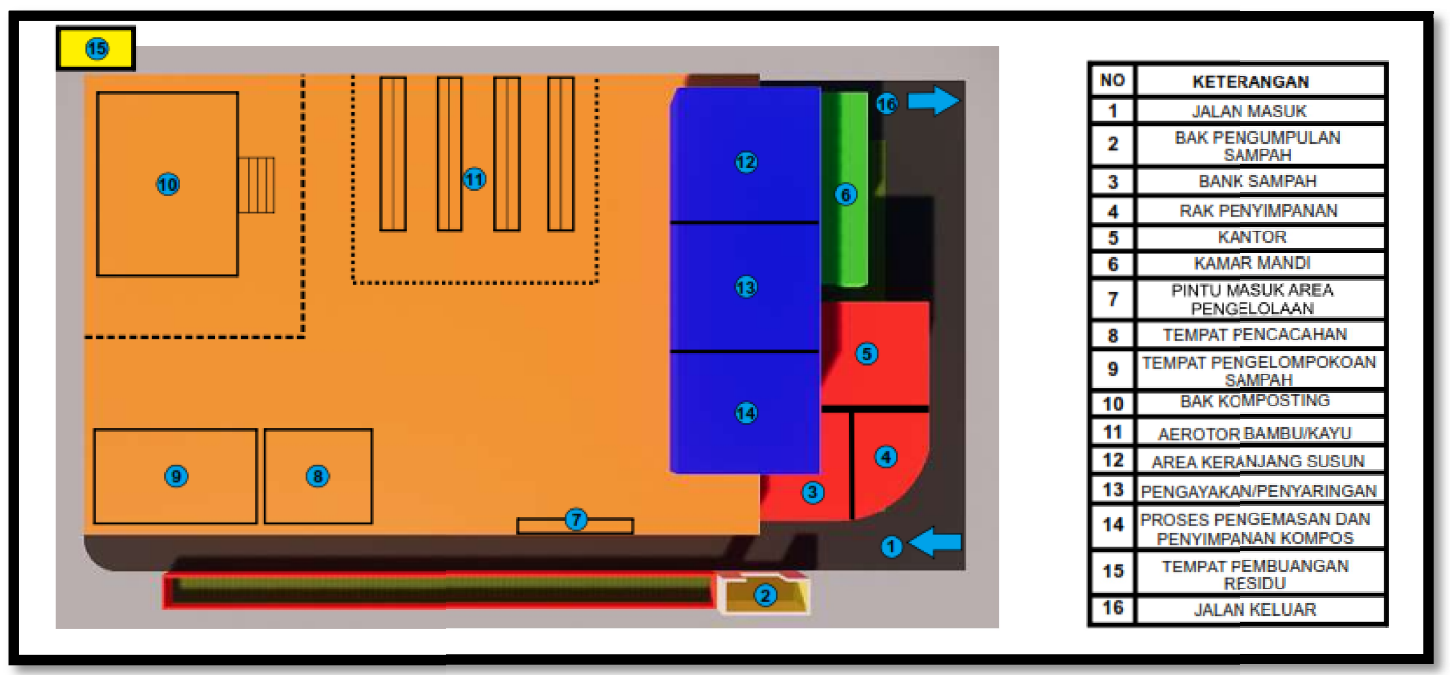

Gambar 8Analisis Zoning Bangunan

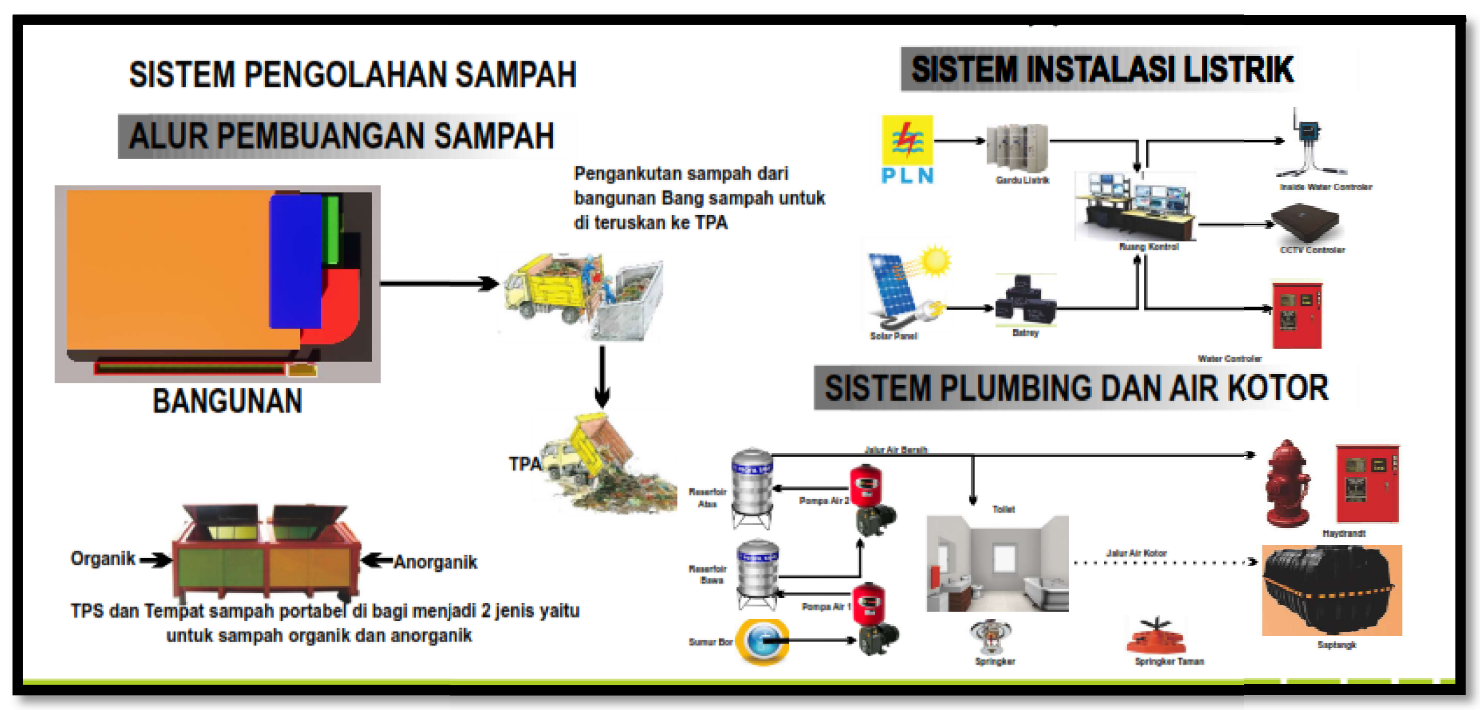




\subsection{KonsepModel Desain Bangunan Bank Sampah}

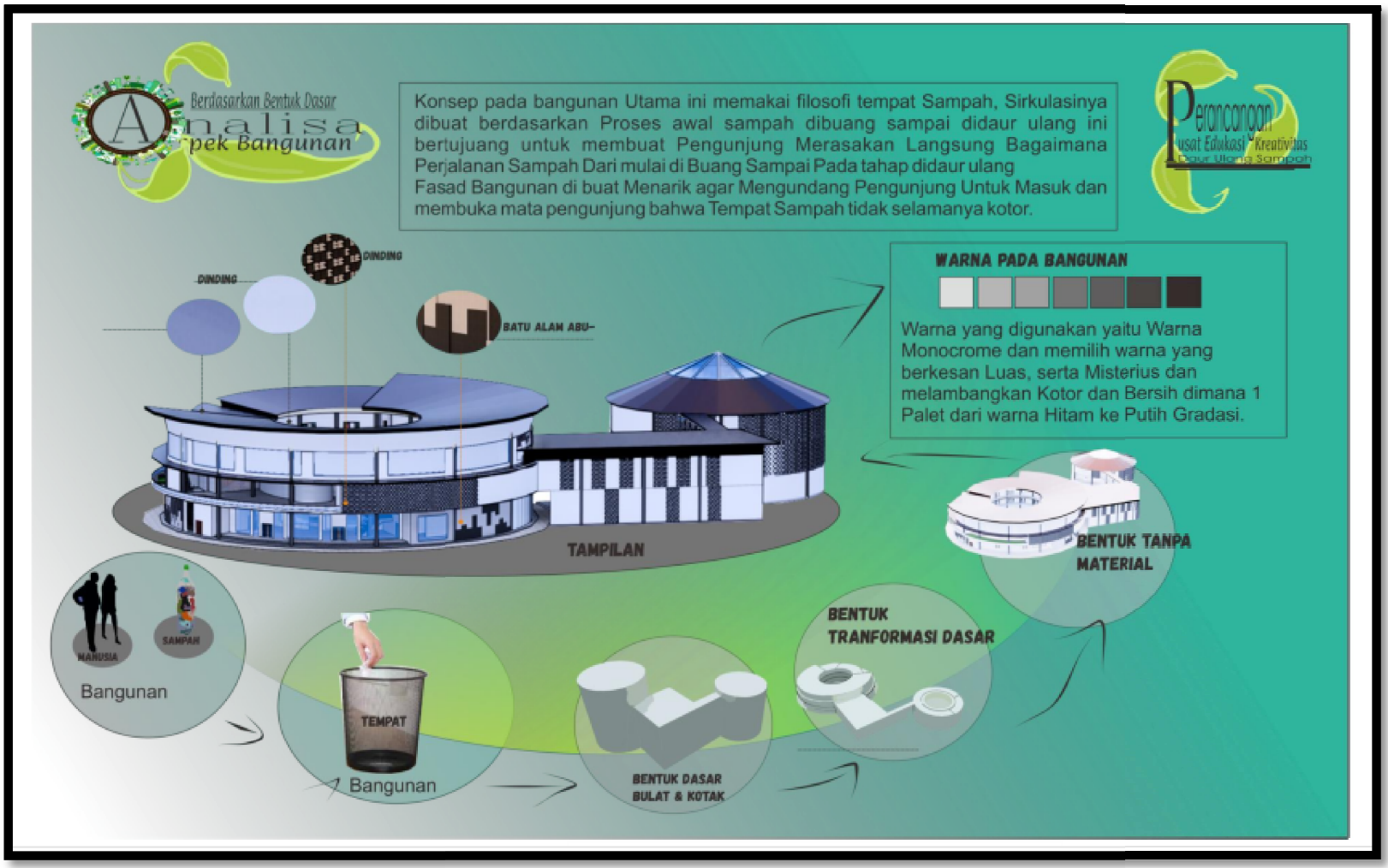

Gambar 10 Konsep Desain Bangunan Bank Sampah

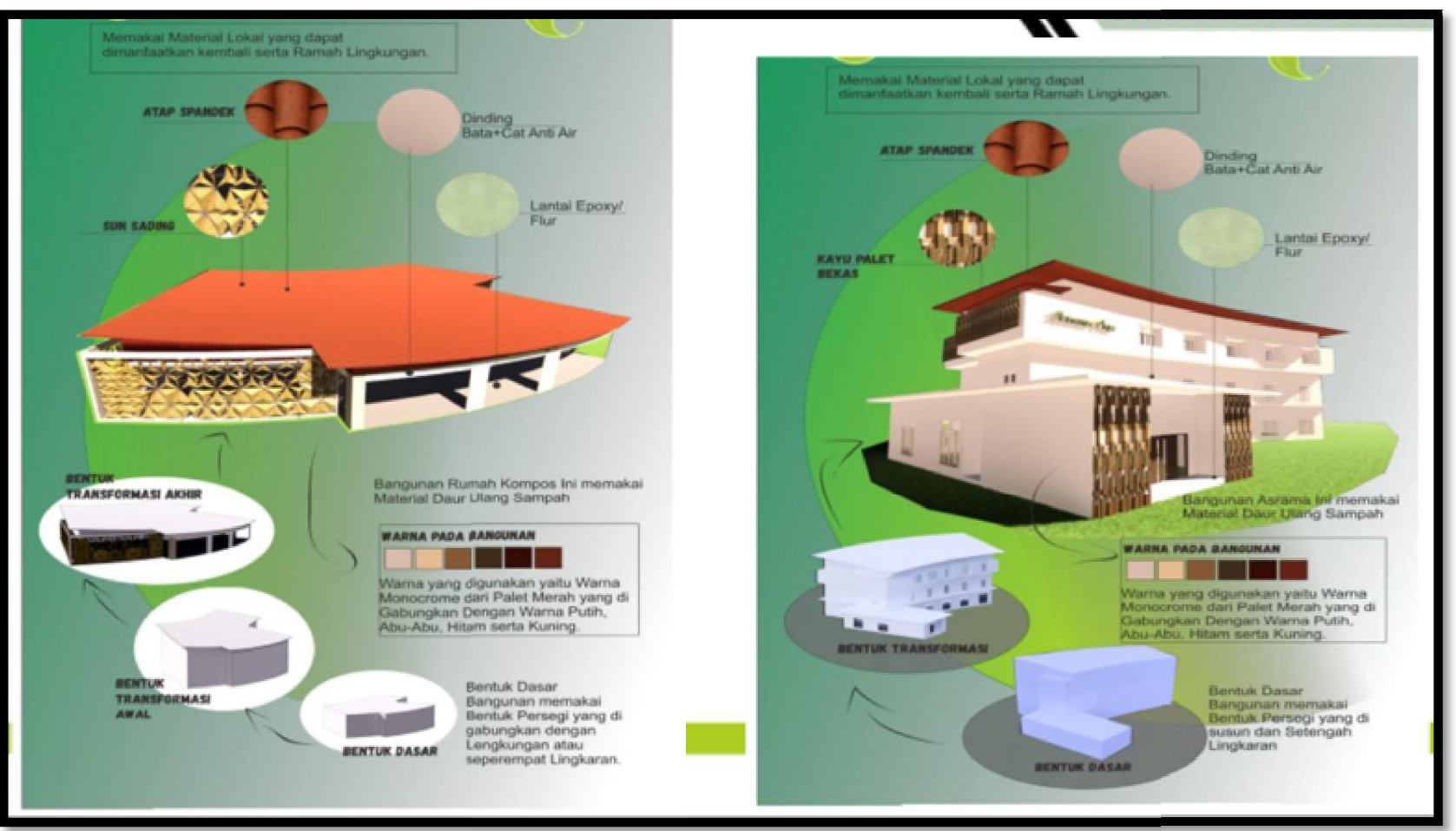

Gambar 11Konsep Desain Material Bangunan Bank Sampah

Vol. 4 No. 2 Oktober (2021) 88-96 | http://ejournal.unkhair.ac.id/index.php/josae | ISSN 2621-3435| 


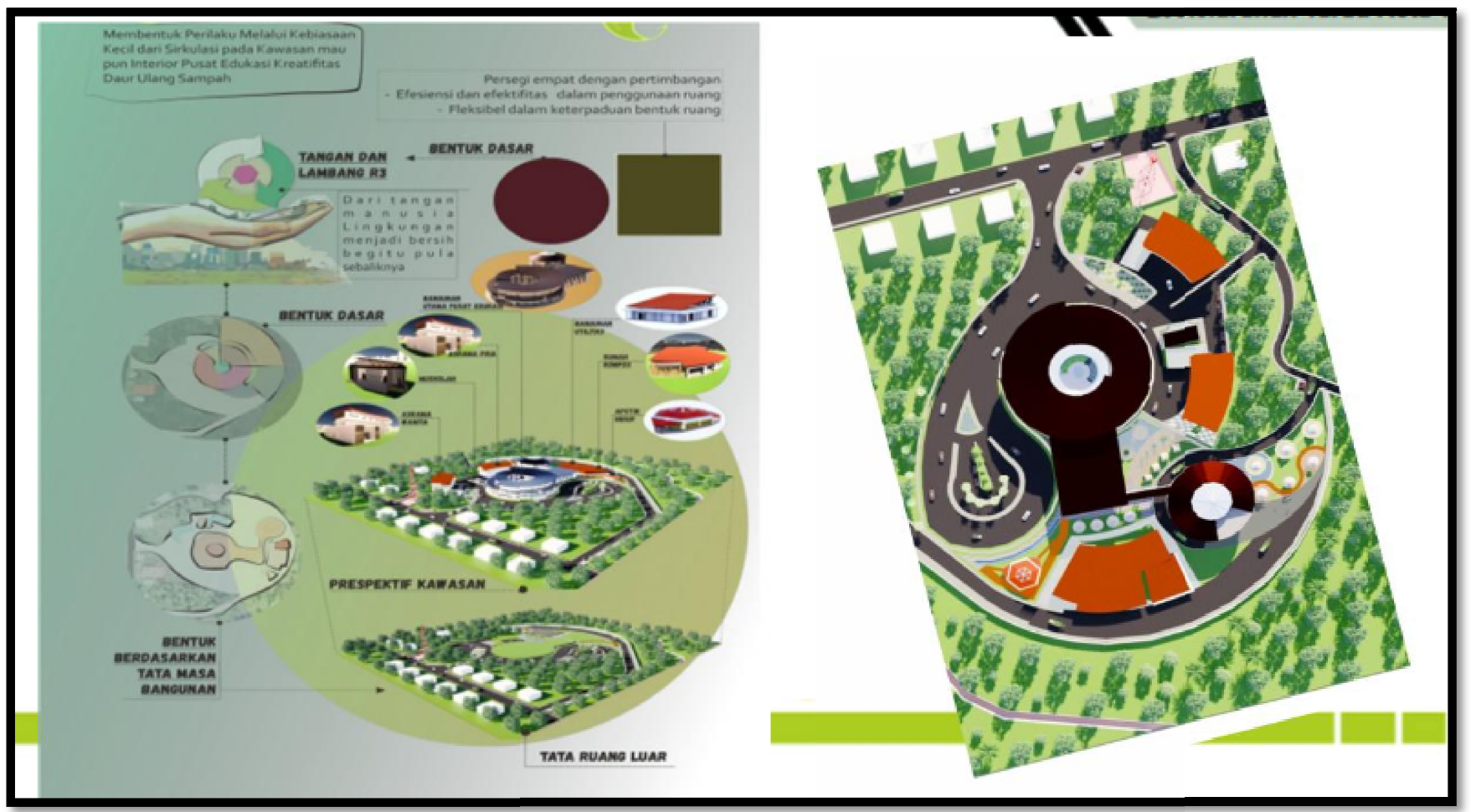

Gambar 12Key Plan Kawasan Bangunan Bank Sampah

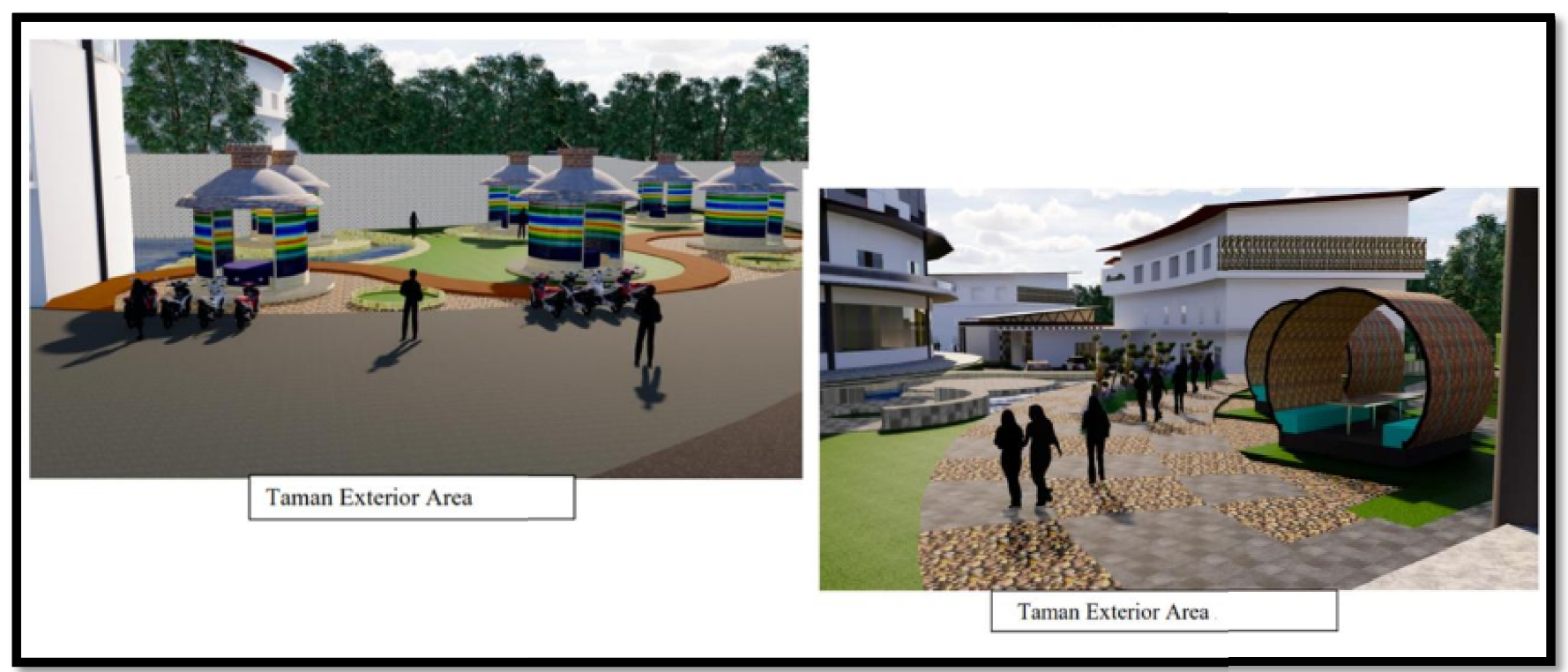

Gambar 13 Perspektif Model Desain Bangunan Bank Sampah

\subsection{KESIMPULAN}

Analisis Model Desain Bangunan Bank Sampah Di Kelurahan Tarau Kecamatan Kota Ternate Utara, mempunyai fungsi sebagai wadah pendidikan non formal bagi masyarakat, terutama masyarakat kalangan 
bawah yang dididik untuk menjadi pengrajin, dan juga membantu masyarakat serta mendidik anak-anak agar dapat memahami tentang lingkungan sekitar serta bagaimana tahapan proses pengolahan sampah organik maupun an-organik. Bangunan Bank Sampah Di Kelurahan Tarau ini tidak menggunakan pendekatan, namun, menyelaraskan edukasi lingkungan dengan Arsitektur Ekologi atau Ramah Lingkungan.

Fasilitas Bangunan Bank Sampah Di Kelurahan Tarau yang diterapkan dalam bangunan yaitu, Area Pemilahan, Area Kompos, Area Energi, Area Kerajinan dan Area Ruang Terbuka Pablik. Sebagai satu kesatuan untuk memberikan Edukasi Pengolahan atau Daur ulang sampah.

Konsep bentuk kawasan yang di gunakan yaitu, suatu inti dalam pengolahan sampah, dimana manusia menjadi penggerak, mesin sebagai pengolah dan $3 \mathrm{R}$ sebagai Prinsip atau ajakan untuk mendaur ulang sampah kepada masyarakat untuk sama- sama membangun lingkungan jauh lebih baik dari gotong - royong atau usaha bersama.

\subsection{Saran}

Masyarakat sebagai bagian dari lingkungan yang seharusnya mengolah lingkungan dan tidak mencemari.Faktor utama dalam pengolahan sampah yaitu pengetahuan dan sebuah rasa kepedulian masyarakat. Saran yang dibutuhkan masyarakat dalam perancangan ini yaitu sebaiknya pemerintah ataupun lembaga terkait menyediakan Fasilitas yang dapat membangun Budaya masyarakat dalampengolahan sampah.

\section{Daftar Pustaka}

[1] S. Yusa Eko Saputro, Kismartini, "Pengelolaan sampah berbasis masyarakat melalui bank sampah," Indones. J. Conserv., vol. 04, pp. 83-94, 2015.

[2] A. S. Suryani, “( STUDI KASUS BANK SAMPAH MALANG ) ( A Case Study of MalangWaste Bank ) Anih Sri Suryani," Aspirasi, pp. 71-84, 2014.

[3] Bada Pusat Statistik Kota Ternate, "Kota Ternate Dalam Angka 2018," 2018.

[4] J. Sahil, M. Henie, I. Al, F. Rohman, and I. Syamsuri, "Sistem Pengelolaan dan Upaya Penanggulangan Sampah Di Kelurahan Dufa- Dufa Kota Ternate,” Bioedukasi, vol. 4, no. 2, 2016.

[5] Kementerian Negara Lingkungan Hidup, "PERATURAN MENTERI NEGARA LINGKUNGAN HIDUP REPUBLIK INDONESIA NOMOR 13 TAHUN 2012 TENTANG PEDOMAN PELAKSANAAN REDUCE, REUSE, DAN RECYCLE MELALUI BANK SAMPAH,” 2012.

[6] T. Aryenti, Kustiasih, "KAJIAN PENINGKATAN TEMPAT PEMBUANGAN SAMPAH SEMENTARA SEBAGAI TEMPAT PENGELOLAAN SAMPAH TERPADU Increasing of Temporary Disposal Site as an Integrated Waste Management," Permukiman, vol. 8, no. 2, pp. 89-97, 2013.

[7] W. P. Bahtiar, Zulkifli Ahmad, "Sampah Rumah Tangga di Ternate Sampah Rumah Tangga di Ternate," no. May, 2019.

[8] I. I. R. Endang Wahyuningtyas, Lubena, "model skematik desain bangunan Bank Sampah di Depok Jawa Barat," vol. 2, no. 1, pp. 1-9, 2017. 